\title{
Opaque for the reader but transparent for the brain: Neural signatures of morphological complexity
}

\author{
Marcus Meinzer ${ }^{\mathrm{a}, \mathrm{b}, \mathrm{d}, *}$, Aditi Lahiri ${ }^{c}$, Tobias Flaisch $^{\mathrm{b}}$, Ronny Hannemann ${ }^{\mathrm{a}}$, Carsten Eulitz ${ }^{\mathrm{a}}$ \\ ${ }^{2}$ Department of Linguistics, University of Konstanz, Germany \\ bepartment of Pychology, University of Konstanz, Germany \\ 'Department of Linguistics, Oxford University, United Kingdom \\ "University of Florida, Department of Clinical and Heatth Psychology 8 Malcolm Randall VAMC, Brain Research and Rehabilitation Center, \\ Gainesville, FL, United Stares
}

\section{A R TICLE I N F O}

\section{Article history:}

Received 29 July 2008

Received in revised form 1 January 2009

Accepted 4 March 2009

Available online 13 March 2009

Keywords:

Language processing

Morphology

Derivational processes

Functional magnetic resonance imaging

\begin{abstract}
A B S T R A C T
Within linguistics, words with a complex intemal structure are commoniy assumed to be decomposed into their constituent morphemes (e.g., un-help-ful). Nevertheless, an ongoing debate concerns the brain structures that subserve this process. Using functional magnetic resonance imaging, the present study varied the internal complexity of derived words while keeping the external surface structure constant as well as controlling relevant parameters that could affect word recognition. This allowed us to tease apart brain activations specifically related to morphological processing from those related to possible confounds of perceptual cues like word length or affix type. Increased task-related activity in left inferior frontal, bilateral temporo-occipital and right parietal areas was specifically related to the processing of derivations with high complex internal structure relative to those with low complex internal structure. Our results show, that morphologically complex words are decomposed and that the brain processes the degree of internal complexity of word derivations.
\end{abstract}

\section{Introduction}

Word recognition is affected by several fundamental linguistic properties. These include meaning (semantics), sound patterns (phonology) as well as visual form (orthography). Furthermore, most words possess a complex internal structure (i.e., morphology). Broadly speaking, words can be morphologically complex in two ways: Inflectional morphology generates grammatical variants, often with the addition of affixes (e.g., play, play-ed), while grammatical class remains unchanged. Derivational morphology creates new words or lexical items and may change the grammatical class of a word (e.g., verb: govern vs. noun: govern-ment), again frequently by adding derivational affixes to the stem.

In particular, research on the potential decomposition of morphologically complex word forms allows studying some of the fundamental questions regarding the organization of the mental lexicon. For instance, traditional linguistic accounts suggest that the mental lexicon is organized morphemically, e.g., during word recog-

\footnotetext{
* Corresponding author at: University of Florida, Department of Clinical and Health Psychology Malcolm Randall VAMC, Brain Research and Rehabilitation Center, 1601 Archer Rd., Gainesville, FL 32608, United States. Tel.: +1 35237616114710 ; fax: +13522650468

E-mail address: mmeinzeroufledu (M. Meinzer).
}

nition words are broken down into their constituent morphemes (e.g., Marslen-Wilson, Tyler, Waksler, \& Older, 1994). On the other hand, connectionist approaches do not assume a morphological level of representation and morphological effects are interpreted by the interplay of semantic and form-based factors (Gonnerman, Seidenberg, \& Andersen, 2007; Rueckl, Mikolinski, Raveh, Miner, \& Mars, 1997; Seidenberg \& Gonnerman, 2000).

There has been growing evidence that morphological processing exerts influence on word recognition and involves decomposition of words into their constituent morphemes (e.g., Marslen-Wilson \& Tyler, 2007; Rastle, Davis, Marslen-Wilson, \& Tyler, 2000; Taft \& Forster, 1975). This has been supported by a number of behavioural and electrophysiological studies (for a review of the latter see Lavric, Clapp, \& Rastle, 2007). For instance, recognition of a printed word (e.g., depend) is facilitated when it is preceeded ('primed') by one of its inflectional variants (e.g., depend-ed) or derivational variants (e.g., in-depend-ent-ly) (Bentin \& Feldman, 1990; Drews \& Zwitserlood, 1995) and words derived from high frequency stems are recognized faster than words derived from low-frequency stems (Niswander, Pollatsek, \& Rayner, 2000; Schreuder \& Baayen, 1997). Moreover, a number of studies suggested that both inflected and derived words undergo an initial obligatory process of segmentation into their morphemic components, irrespective of whether the words actually are morphologically complex' (cf., MarslenWilson \& Tyler, 2007, p. 831). This is supported by studies that 
found selectively impaired decompositional processing in patients with non-fluent aphasia not only for regularly inflected words but also for potentially decomposable non-words with a regular inflectional affix (e.g., Longworth, Marslen-Wilson, Randall, \& Tyler, 2005; Tyler, Randall, \& Marslen-Wilson, 2002). A similar lexically blind early segmentation has recently been observed for (English and French) derivational morphology in a number of behavioural studies (Longtin \& Meunier, 2005; Rastle et al., 2000) and confirmed by recent functional imaging and electrophysiological studies (for details see below). Nevertheless, the question remains whether or not the internal structure of words represents a core feature of word recognition, thus providing a general principle of linguistic processing independent of form and meaning and whether morphological decomposition is subserved by distinct brain areas (Davis, 2004).

Converging evidence from a number of behavioural and functional neuroimaging studies (functional magnetic resonance imaging. (MRI) in healthy and brain damaged individuals confirmed that in particular left inferior frontal brain regions are specifically implicated with morphological decomposition of regularly inflected words (Dominguez, de Vega, \& Barber, 2004; Miceli et al., 2002; Shapiro, Pascual-Leone, Mottaghy, Gangitano, \& Caramazza, 2001; Tyler, Marslen-Wilson, \& Stamatakis, 2005; Tyler et al., 2002). Crucially, however, studies concerned with the neural signatures of derivational morphology are scarce and inconsistent results are reported in the literature. For instance, Devlin, Jamison, Matthews, and Gonnerman (2004) employed a masked priming paradigm during fMRI (i.e., the preceeding prime is presented subliminally to the subjects immediately before the target stimulus) and no specific effects for morphologically related English words were found, particularly not in left frontal regions. Rather, morphological priming effects overlapped with those of orthographic effects in left posterior occipito-temporal brain regions and with those of semantic effects in the left middle temporal gyrus. On the other hand, by using event-related fMRI and a delayed repetition design (i.e., prime and target are separated by a long time interval of $45 \mathrm{~s}$ ), Bozic, Marslen-Wilson, Stamatakis, Davis, and Tyler (2007) demonstrated left inferior frontal regions to be sensitive for morphological priming. In line with recent EEG findings (Lavric et al., 2007) the authors conclude that at the earliest stage of written (English) word recognition, words are decomposed into their stems and affixes, and that this process potentially holds for all complex words. More over, Davis, Meunier, and Marslen-Wilson (2004) compared activity patterns for English words which differed in morphological complexity by using fMRI during a one-back synonym monitoring task and found no differences between simple monomorphemic words and complex derived or inflected words, which argues against a specialized processing for morphologically complex words.

Using alternative experimental setups, Marangolo, Piras, Galatí, and Burani (2006) directly compared brain activity patterns of healthy subjects during several derivational tasks in Italian (e.g., silent generation of a derived noun from an adjective) and inflectional tasks (e.g., produce the plural forms of adjectives). Interestingly, the derivational task specifically activated the left ventrolateral frontal cortex and additional regions in the parietal lobe bilaterally. This additional right hemispheric involvement during derivational processing has been supported by a dual case study (Marangolo et al., 2003) that demonstrated selective deficits in the processing of morphologically derived Italian words in two patients with right hemispheric lesions involving temporo-parietal structures. Thus, previous studies on the neural substrate of morphological decomposition yielded inconclusive results.

From a linguistic point of view, previous experiments were looking for rather large scale differences by comparing derivational with inflectional morphological processes or comparing the processing of decomposable with non-decomposable words. Naturally, these studies examined different types of derivational processes and thus did not systematically vary the morphological complexity while keeping other factors like word-class, number of letters or syllables, frequency, visual complexity, or imageability constant. Therefore, the present study was designed to study derivational morphological processes using an alternative strategy. Given the fundamental claim that morphological decomposition is obligatory for all words (or non-words) that appear morphologically complex (Bozic et al., 2007; Lavric et al., 2007; Marslen-Wilson \& Tyler, 2007) (a) reading words with a complex internal structure should trigger decompositional processes and (b) a direct comparison of decomposable words of different complexity in a parametric design should evoke a graded pattern of morphological processing.

Hence, in the present study we used fMRI to compare the neural signatures of reading derived German nouns with a high or low complex internal structure. Both types of nouns were complex: they comprised the same suffix and thus the same surface structure. However, the conditions differed with regard to their internal structure, that is, the number of steps required for the derivation: For example, the German nouns 'Deutung' (interpretation) and 'Milderung' (mitigation) look superficially similar, since both hold the suffix '-ung'. Nevertheless, the former is derived in a single step (1-step condition) from the verb 'deuten', while the latter is derived in two steps from the adjective via a verb ('mild' $=>$ ' mildern' $=>$ 'Milderung"; 2-step condition). In terms of alternative parameters which might index a difference between the words, like word-class, suffix, word-frequency. family-size, number of letters and syllables, the stimulus material was matched.

We hypothesized that nouns with a 2-step derivation would elicit more pronounced activity in the neural networks supporting morphological decomposition, i.e., mainly in left inferior frontal as well as bilaterally in posterior brain regions. Such activation would provide evidence for neural traces supporting the more demanding processing/segmentation demands (Marslen-Wilson \& Tyler, 2007; Ullman, 2001) during the automatic decomposition of highly complex nouns that appear to be similar to-less complex nouns, at least superficially.

\section{Methods}

\subsection{Participants}

Twenty-four healthy native speakers of German (mean age $26.1 \pm 6.2$ years. 15 females, 9 males) were recruited for the study. All were strongly right-handed as assessed with the Edinburgh inventory (Oldfield, 1971). Subjects were briefed on scanner security, gave written informed consent and were paid $€ 10$ for participation. Ethical approval was granted by the local ethics committee.

\subsection{Experimental task}

We employed a lexical decision task, in which participants bad to detect pronounceable but senseless non-words. Participants were instructed that they would see blocks of nouns, unpronounceable letter strings and a series of fixation crosses (null-baseline) at the centre of a video screen and that the non-words would appear in between the words and letter strings at variable positions within blocks.

\subsection{Stimulus characteristics}

Overall we used 72 words, half of them 1-step derivations, the other half 2step derivations (i,e., 36 items of each category, 18 derived from a verb or an adjective). In particular, stimuli consisted of (less complex, 1-step) nouns that can be derived through a single step of conversion either from an adjective or verb le.g.. verb 'erobern' (to conquer) $\Rightarrow$ noun 'Eroberung' (conquest); adjective 'müde' (tired) $\Rightarrow$ noun 'Müdigkeir' (tiredness)]. In contrast, more complex nouns (2-step condition) entail an intermediate processing step le.g., verb 'lesen' (to read) $=>$ adjective 'lesbar' (readable) $=>$ noun 'Lesbarkeit' (readability); adjective 'mild" (mild) $=>$ verb 'mildem' (milden) $=>$ noun 'Milderungt). Note that during the MRI recordings, only the derived nouns were presented and that the set of nouns consisted of 36 different words per condition. 1-step nouns derived from verbs ended with the suffix '-ung', while 1-step nouns derived from adjectives ended with the suffix '-keit'. 2-step nouns derived from verbs ended with '-keit' and 2-step nouns derived from adjectives ended with '-ung'. Therefore, both categories of stimuli contained both types of suffixes at an equal propertion. The words used for the present study are listed in Supplementary Table 1. 
Both sets of stimuli were matched for written word-frequency (taken from CELEX, 1-step nouns: frequency $\emptyset 23.7 \pm 26.9 ; 2$-step nouns: mean frequency $\emptyset$ $19.8 \pm 30.4 ; F(1,70)<1, p>.56$ ), word length (1-step $09.3 \pm 2.2,2$-step $\emptyset 9.9 \pm 2.5$; $F<1, p>34$ ), number of syllables (1-step $02.6 \pm 0.7,2$-step $42.6 \pm 0.6 ; F=0, p=1$ ). Both stimulus categories were also comparable in terms of morphological familysize (1-step: $32.4 \pm 37.32$-step words: $33.9 \pm 27.5, F=.03, p>.85$. Dejong, Schreuder, \& Bayen. 2000 ). The number of orthographic neighbours was comparable between the two conditions (CELEX, 1-step words: $0.25 \pm 0.60$; 2 -step words: $10.28 \pm 0.56$; $F(1,70)=04, p-84$ ). Lexical stress was mostly word initial and only two words per condition had the stress on the second syllable, but never word final

Twenty subjects (who did not participate in the fMra study: 11 females, 9 males; age range 20-35 years) rated the entire set of stimuli for imageability and concreteness on a 7-point scale $(0$ indicating low and 7 indicating high imageability/concreteness). Ratings were found to be equivalent for 1 - and 2 -step nouns $(1$-step $5.0 \pm 0.7,2$-step $5.2 \pm 0.9 ; F<1 . p>4)$. Additionally, we conducted a behavioural experiment (16 subjects who did not participate in the fMRI study: 10 females, 6 males, age range 21-32) testing whether the participants were aware of the difference between $1-$ and 2-step complex words. Using a computerized forced choice design subjects were presented with pairs of words 14 condi-

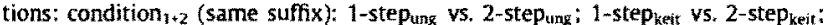
condition $_{3+4}$ (different suffix): 1-stepkeit vs. 2-stepung; 1-stepung vs. 2-stepket"]. The subjects' task was to indicate which word of each pair was perceived to be more complex (left/right button press) or if the words were perceived as equally complex (downward arrow). Responses were subsequently rated on a 3-point scale (1:2step $>1$-step; -1: 1-step $>2$-step; $0: 1$-step $=2$-step). In the condition that comprised words with different suffixes the subjects consistently rated the word with the suffix 'keit' as more complex, irrespective of its actual complexity (2-step $\mathrm{keit}>1$-ste $p_{\mathrm{ung}}$ $0.55 \pm 0.41$; Wilcoxon Signed Rank (SR) Test $=56.5, p<.001 ; 1$-step $\mathrm{p}_{\mathrm{kej}}>2$-step $-0.35 \pm 0.34 ; S R=-56.5, p=.002$ ). In both 'same suffix' conditions the average ratings of the 16 subjects indicated that 1 - and 2 -step words were perceived as equally complex ('keit' $0.01 \pm 0.17$; 'ung' $(0.13 \pm 0.21$ ). A Wilcoxon Signed Rank Test indicated that ratings were not different from zero ('keit': $S R=1, p=90$; “ung': $S R=4.5$, $p=63$. Thus, as the stimuli in our IMRl experiment were balanced for the types of suffixes we are confident that the subjects in our study were not aware of the more pronounced but hidden morphological complexity of the 2-step complex words.

Unpronounceable letter strings (for the baseline blocks during $\mathrm{MRI}$ ) were obtained by scrambling the letters of the 1- and 2-step nouns used for stimulation and were therefore perfectly matched for length/visual appearance to the nouns, Pronounceable non-words (for the lexical decision task) were derived from German words (matched for frequency and length to the 1-and 2-step nouns) by scrambling vowels and consonants. All non-words were orthographically and phonologically regular.

\subsection{IMRI setup}

Functional MRI stimulation consisted of 5 blocked conditions (1- and 2-step complex nouns, 2 letter-string baselines for each of the experimental conditions, fixation cross baseline). Each block comprised six stimuli and one readable non-word. The null-baseline included only fixation crosses ( $N=7$ in each block). The total length of each block was $12 \mathrm{~s}$. Each stimulus was presented for $1200 \mathrm{~ms}$ with a fixed interval between stimuli (blank screen). The total duration of the experiment was $12 \mathrm{~min}$.

Blocks of words alternated with letter strings ( 6 blocks), with interspersed blocks of fixation crosses ( 3 blocks) at the end of each run (e.g., 2-step complex nouns-letter strings-1-step complex nouns-letter strings-null-baseline, etc. The total sequence of stimuli was presented twice. The sequence of blocks was fixed while presentation of stimuli within blocks was randomized. Two different sequences of blocks were designed and equally assigned to the subjects. Sequential probabilities that a word-class (1-and 2-step complex nouns) was preceded by a null-baseline or any of the letter baselines were counterbalanced across the subjects. Non-words were presented either at the beginning $(N=2)$, in the middle $(N=2)$ or at the end of each block $(N=2)$ across the experiment. The appearance of non-words within blocks was randomly varied within and across subjects [Note: The 'control-task', i.e. itetection of non-words within blocks of derived words, was exactly the same for the 1- and 2 step conditions and successful detection of non-words was comparable between the two conditions (see Section 3). Thus, we assume that the nature of the control task did not influence the activity patterns found during the two experimental conditions. in particular, the direct comparison of 1 - and 2-step nouns was not influenced)

Stimuli were presented by a visor (VisuaStim, Resonance Technology. Inc.) and the subjects were instructed to carefully read the stimuli in silence and to indicate detection of a pronounceable non-word by lifting the thumb of the right hand. Correct detection of non-word-targets was recorded by the experimenter who observed performance through a window in the scanner room. Stimuli were presented using presentation software (Neurobehavioral Systems, Inc.) in upper case Arial font (font size 44 ) in the middle of the screen.

\subsection{Scanting parameters}

Scanning was conducted using a 1.5T Philips Intera MR-System equipped with Power Gradients. For functional scanning, a T2*-weighted Fast-Field Echo, EchoPlaner-lmaging (FFE-EPI) sequence utilizing a parallel scanning technique [SENSE;
Pruessmann, Weiger, Scheidegger, \& Boesiger, 1999] was used. Images were acquired in transversal orientation parallel to the $\mathrm{AC}-\mathrm{PC}$ line. Each dyna mic volume consisted of 38 slices measured in interleaved acquisition order with a thickness of $3 \mathrm{~mm}$ each with an interslice gap of $0.5 \mathrm{~mm}$. In plane resolution was $3 \mathrm{~mm} \times 3 \mathrm{~mm} \times 3 \mathrm{~mm}$ with a squared Field-of-View at a size of $240 \mathrm{~mm}$ (acquisition matrix $80 \times 80$ voxels; $T E=40$; flip angle $=90$ ). One whole head scan was measured every $3 \mathrm{~s}$ (TR) and overall the sequence consisted of 240 continuously acquired volumes. At the beginning of the experimental session, 8 dummy scans were acquired to allow for T1-equilibration, these scans were discarded from data analysis.

\subsection{Functional MRI post-processing}

Functional MRI post-processing was performed using Statistical Parametric Mapping (SPMS, Wellcome Department of Cognitive Neurology, London, UK). Preprocessing included correction for slice-time differences and spatial alignment to the first volume in the image series to adjust for head movements during the experiment. Afterwards, functional volumes were normalized to MNI standard stereotactic space and smoothed with a Gaussian Kernel of $9 \mathrm{~mm} \times 9 \mathrm{~mm} \times 9 \mathrm{~mm}$ full-width-athalf-maximum (FWHM)

After preprocessing, the data were submitted to statistical analysis implementing the General Linear Model (GLM). The corresponding design matrix comprised the 5 covariates-of-interest representing the experimental conditions' onsets and the duration of the different presentation epochs, as well as covariates-of-no-interest The latter included the six movement parameters obtained during realignment and one covariate incorporating an overall intercept to the model. The covariates-ofno-interest were included to improve overall model fit to the empirical data and to reduce residual error variance, in effect increasing overall statistical power of the model. Before estimating the modeled regressors, a high pass filter with a cut-off period of $128 \mathrm{~s}$ was applied to the data. Following estimation of the overall model, planned contrasts of-interest were calculated for each subject. These included separate comparisons of 1- and 2-step nouns to the null-baseline, to determine areas associated with reading. Moreover, we directly contrasted morphologically more or less complex nouns. This contrast included correction by the complex letter-string baseline to control for basic visual features of the two word classes since 2-step words were slightly longer than 1-step nouns [i.e., (Words ${ }_{2 \text {-step }}$ Letters 2 -step $)>\left(\right.$ Words $_{1-\text { step }}$-Letters 1 -step $)$.

For the group analysis a random effect model was calculated that included the above mentioned contrasts of all subjects. Common activity patterns associated with both types of derivations (1- and 2-step words) were determined by means of an inclusive masking procedure, comparing the contrast of 2 -step words vs. the null baseline with the contrast of 1 -step words vs, the null-baseline. Maximally activated voxels within significant clusters are reported (cluster threshold $p<.05$ family-wise error-corrected. FWE, cluster extent $k>20$; voxel threshold $p<.001$ uncorrected) Anatomic localization of significant voxels within clusters was conducted using the Talairach Demon softwate (lancaster et al, 2000). For graphical display activated areas are projected onto a template of a standard MNI brain.

\section{Results}

Detection of readable pseudoword targets that were interspersed between blocks of 1- and 2-step nouns during the lexical decision task in the scanner was high (>95\%) for all subjects in both experimental conditions, which confirms compliance to the task. Detection of pseudowords between the two experimental conditions was comparable $(F<1)$. Moreover, we did not observe 'false positive' responses (i.e., none of the participants raised their thumb when a real word was presented). Thus, we are confident that they paid attention to the task and also identified real words as real words. After the experiment, the participants were asked as to whether or not they were aware of any differences between words. Although they reported that different suffixes were used, none of the participants was aware about the critical 1- and 2-step difference. Moreover, in an additional behavioural experiment the two types of complex words were rated as equally complex by a different group of subjects when the types of suffixes were matched as in our MRI study (see Section 2).

Inspection of the basic contrasts of 1- and 2-step nouns against the null-baseline revealed a pattern of activity very similar to that reported in previous studies of single word reading using functional imaging techniques (Binder et al., 2003; Mechelli, Gorno-Tempini, \& Price, 2003; Price, 2000; Price \& Mechelli, 2005; Turkeltaub, Eden, Jones, \& Zeffiro, 2002). In particular, a large cluster of activity, in part related to the processing of visual attributes of the stimuli, in parieto-occipital areas of both hemispheres was confirmed for both 


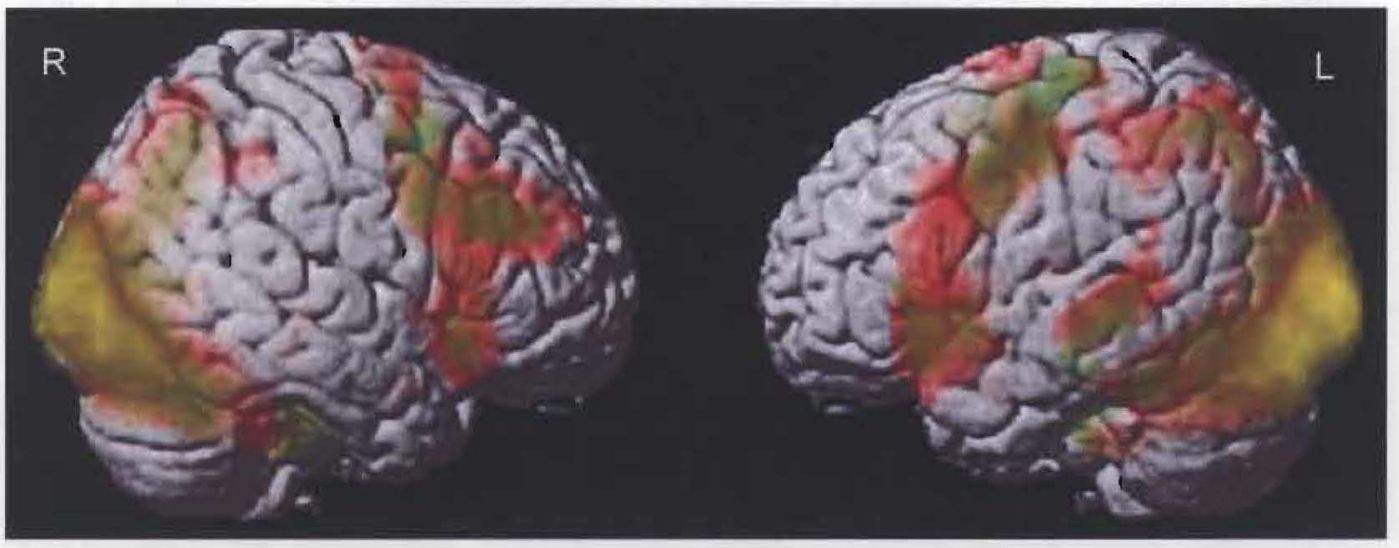

Fig. 1. The general activity pattern during the lexical decision task for simple and complex nouns vs. the baseline condition as an overlay plot rendered on the standard MNI template. Yellow: overlapping activity for borh types of complex nouns (1- and 2-step). Red: additional activity elicited by 2 -step nouns.

conditions (1- and 2-step nouns). Additional activity was substantiated in left fronto-temporal regions including the inferior frontal (BA 47), anterior superior and posterior middle temporal gyrus (BAs 21/22) and additional right frontal areas.

For illustrative purposes the activity patterns for both types of complex nouns compared to the null-baseline is shown in Fig. 1 as an overlay plot rendered on a standard brain template. Here, yellow indicates an overlap of activity elicited by 1 - and 2 -step nouns, while red is indicative of additional activity elicited by 2 -step nouns and green for more pronounced activity elicited by 1-step nouns. Both conditions showed very similar patterns of activity, indicating that both types of derivations reliably engaged major parts of the reading cascade (for the statistical analysis of differences between conditions see below).

Details for common activity elicited by both 1- and 2-step complex nouns are provided in Table 1 and included bilateral occipital and parietal cortices, with peak activity being strongly left-lateralized. Additional activity common to both experimental conditions comprised a large left-lateralized network that included the middle and superior temporal gyrus, the precentral gyrus and inferior/medial frontal areas. Right hemispheric areas activated by both conditions included the middle and inferior frontal gyrus.

The main effect of interest, the direct comparison of the two experimental conditions, revealed more pronounced activity for complex 2-step nouns compared to 1-step nouns (Fig. 2): In particular, this was substantiated for the left inferior frontal gyrus (BAs $44 / 45 / 9 ; k=52$; peak activity: $Z=4.19 ; x / y / z-50 / 16 / 21$ ), the left middle and superior temporal gyrus (BAs 22/41; $k=105$; peak activity: $Z=4.75 ;-62 /-38 / 5$ ) and the right superior temporal gyrus (BAs 21/42: $k=121$; peak activity: $Z=4.58 ; 59 /-32 / 10$ ). Furthermore, increased activity for complex nouns was found bilaterally in posterior occipito-temporal cortices ( $\mathrm{LH}$ : inferior and middle occipital gyrus; BAs $18 / 19 ; k=108$; peak activity: $Z=4.45 ;-39 /-81 / 10$; RH: cuneus and middle temporal gyrus; BAs 18/19/39; $k=133$; peak

Table 1

Common activity associated with both types of complex (1-and 2-step) nouns [i.e., (2-step words-baseline) inclusively masked by (1-step words-baseline)]. Peak activity within significantly activated clusters is reported $(p<.05$. FWE corrected; $k>20 ; p<.001$ uncorrected voxel level).

\begin{tabular}{|c|c|c|c|c|c|c|c|}
\hline Structures & Hemi & $\mathrm{BA}$ & $k$ & $Z$ & $x$ & $y$ & $z$ \\
\hline $\begin{array}{l}\text { Occipital (cuneus) } \\
\text { Middle occipital } \\
\text { Lingual gyrus }\end{array}$ & L/R & 18 & 5489 & $>14$ & $\begin{array}{l}-15 \\
-27 \\
-18\end{array}$ & $\begin{array}{l}-96 \\
-96 \\
-88\end{array}$ & $\begin{array}{r}0 \\
10 \\
-6\end{array}$ \\
\hline $\begin{array}{l}\text { Inferior frontal } \\
\text { Superior temporal }\end{array}$ & L & $\begin{array}{l}47 \\
22\end{array}$ & 239 & $\begin{array}{l}5.72 \\
4.40 \\
4.30\end{array}$ & $\begin{array}{l}-33 \\
-53 \\
-56\end{array}$ & $\begin{array}{r}23 \\
8 \\
17\end{array}$ & $\begin{array}{l}-6 \\
-5 \\
-3\end{array}$ \\
\hline $\begin{array}{l}\text { Precentral gyrus } \\
\text { Inferior fronta! }\end{array}$ & L & $\begin{array}{l}6 / 4 \\
9\end{array}$ & 423 & $\begin{array}{l}5.61 \\
4.93\end{array}$ & $\begin{array}{l}-50 \\
-39\end{array}$ & $\begin{array}{r}-1 \\
4\end{array}$ & $\begin{array}{l}41 \\
30\end{array}$ \\
\hline $\begin{array}{l}\text { Brain stem and basal ganglia } \\
\text { Middle temporal }\end{array}$ & $\begin{array}{l}\mathrm{L} \\
\mathrm{L}\end{array}$ & $\begin{array}{l}21 \\
22\end{array}$ & $\begin{array}{l}209 \\
124\end{array}$ & $\begin{array}{l}4.99 \\
4.69 \\
4.66\end{array}$ & $\begin{array}{r}-9 \\
-56 \\
-59\end{array}$ & $\begin{array}{l}-27 \\
-29 \\
-35\end{array}$ & $\begin{array}{r}-14 \\
-4 \\
2\end{array}$ \\
\hline $\begin{array}{l}\text { Parietal (precuneus) } \\
\text { Superior parietal } \\
\text { Inferior parietal }\end{array}$ & $L$ & $\begin{array}{r}7 \\
40 \\
7\end{array}$ & 125 & $\begin{array}{l}4.33 \\
4.16 \\
3.66\end{array}$ & $\begin{array}{l}-21 \\
-30 \\
-36\end{array}$ & $\begin{array}{l}-68 \\
-59 \\
-41\end{array}$ & $\begin{array}{l}42 \\
53 \\
46\end{array}$ \\
\hline $\begin{array}{l}\text { Medial frontal } \\
\text { Superior frontal } \\
\text { Medial frontal }\end{array}$ & $\begin{array}{l}\mathrm{L} \\
\mathrm{R}\end{array}$ & 6 & 118 & $\begin{array}{l}4.05 \\
4.03 \\
3.79\end{array}$ & $\begin{array}{l}-3 \\
-3 \\
12\end{array}$ & $\begin{array}{r}-3 \\
8 \\
8\end{array}$ & $\begin{array}{l}61 \\
49 \\
49\end{array}$ \\
\hline $\begin{array}{l}\text { Middle frontal } \\
\text { Inferior frontal }\end{array}$ & $\mathbf{R}$ & $\begin{array}{r}46 \\
9\end{array}$ & 293 & $\begin{array}{l}5.68 \\
5.00\end{array}$ & $\begin{array}{l}56 \\
50\end{array}$ & $\begin{array}{l}30 \\
10\end{array}$ & $\begin{array}{l}23 \\
27\end{array}$ \\
\hline Inferior frontal & $\mathbf{R}$ & 47 & 82 & 4.49 & 42 & 20 & -9 \\
\hline
\end{tabular}

$\mathrm{L}=$ left: $\mathrm{R}=$ right: Hemi $=$ hemisphere; $\mathrm{BA}=$ Brodman area; $k=$ cluster extent; $x / y / z=$ Talairach-coordinates, $Z$-values for maximally activated voxels within significant clusters $(p<.05$ FWE-corrected); voxel threshold $p<.001$ uncorrected, $k>40$, anatomic localization of voxels has been determined using the Talairach Demon Software with the nearest gray matter option enabled (Lancaster et al., 2000), peak voxels within significant clusters are reported.

In bold: peak voxel within significant cluster. 


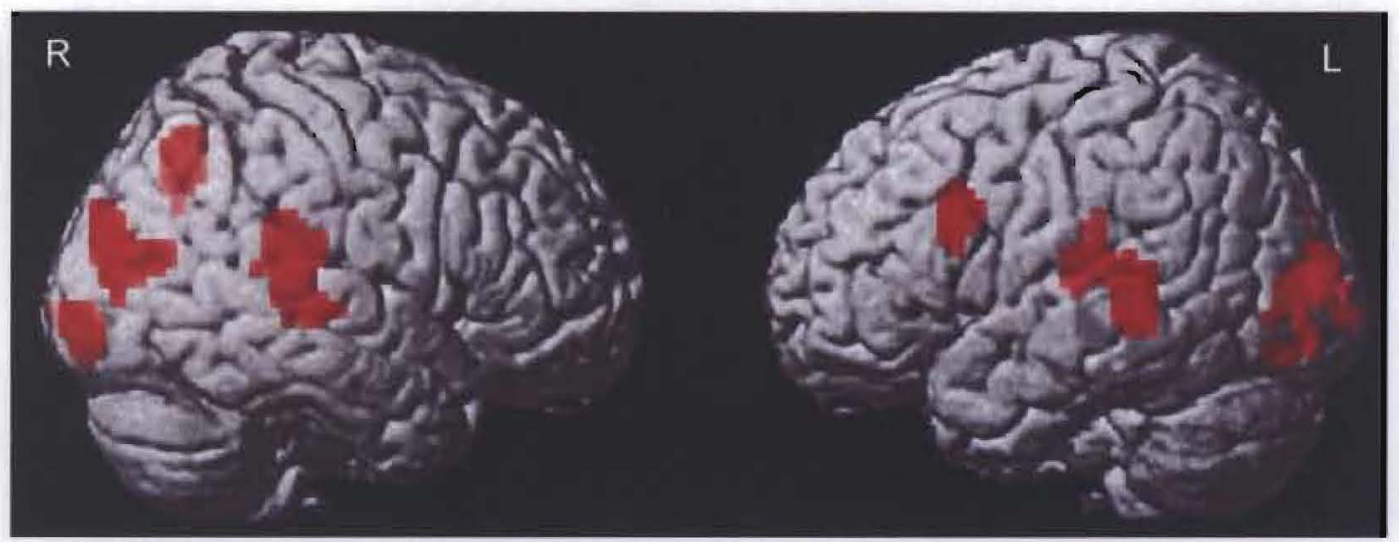

Fig. 2. Depicts more pronounced activity for the processing of highly complex nouns compared to decomposable but less complex nouns (2-step >1-step nouns).

Table 2

Differential activity for morphologically more and less complex nouns: More pronounced activity for morphologically was found for highly complex nouns (2-step nouns) compared to less complex (1-step) nouns. No increased activity was found for the inverse contrast.

\begin{tabular}{|c|c|c|c|c|c|c|c|}
\hline Structures & Hemi & $B A$ & $k$ & $z$ & $x$ & $y$ & $z$ \\
\hline $\begin{array}{l}\text { Inferior frontal } \\
\text { Middle frontal }\end{array}$ & L & $\begin{array}{l}44 / 45 / 9 \\
46 / 9\end{array}$ & 52 & $\begin{array}{l}4.19 \\
3.65\end{array}$ & $\begin{array}{l}-50 \\
-56\end{array}$ & $\begin{array}{l}16 \\
16\end{array}$ & $\begin{array}{l}21 \\
32\end{array}$ \\
\hline $\begin{array}{l}\text { Middle temporal } \\
\text { Superior temporal }\end{array}$ & $L$ & $\begin{array}{l}22 \\
22 / 41\end{array}$ & 105 & $\begin{array}{l}4.75 \\
3.71\end{array}$ & $\begin{array}{l}-62 \\
-65\end{array}$ & $\begin{array}{l}-38 \\
-32\end{array}$ & $\begin{array}{r}5 \\
10\end{array}$ \\
\hline $\begin{array}{l}\text { Middle occipital } \\
\text { Inferior occipital } \\
\text { Lingual gyrus }\end{array}$ & L & $\begin{array}{l}19 / 18 \\
18 \\
18\end{array}$ & 108 & $\begin{array}{l}4.45 \\
3.71 \\
3.56\end{array}$ & $\begin{array}{l}-39 \\
-33 \\
-27\end{array}$ & $\begin{array}{l}-81 \\
-85 \\
-76\end{array}$ & $\begin{array}{r}10 \\
-3 \\
-6\end{array}$ \\
\hline $\begin{array}{l}\text { Parietal (precuneus) } \\
\text { Superior temporal! }\end{array}$ & $\begin{array}{l}\mathrm{R} \\
\mathrm{R}\end{array}$ & $\begin{array}{l}7 \\
21 / 42\end{array}$ & $\begin{array}{r}61 \\
121\end{array}$ & $\begin{array}{l}4.85 \\
4.58\end{array}$ & $\begin{array}{l}24 \\
59\end{array}$ & $\begin{array}{l}-62 \\
-32\end{array}$ & $\begin{array}{l}39 \\
10\end{array}$ \\
\hline $\begin{array}{l}\text { Occipital (cuneus) } \\
\text { Middle temporal }\end{array}$ & $\mathrm{R}$ & $\begin{array}{l}19 / 18 \\
39\end{array}$ & 133 & $\begin{array}{l}4.19 \\
3.65\end{array}$ & $\begin{array}{l}27 \\
42\end{array}$ & $\begin{array}{l}-83 \\
-72\end{array}$ & $\begin{array}{l}21 \\
15\end{array}$ \\
\hline $\begin{array}{l}\text { Inferior occipital } \\
\text { Lingual gyrus } \\
\text { Middle occipital }\end{array}$ & $\mathrm{R}$ & $\begin{array}{l}18 \\
17 \\
18\end{array}$ & 40 & $\begin{array}{l}3.95 \\
3.56 \\
3.39\end{array}$ & $\begin{array}{l}36 \\
21 \\
30\end{array}$ & $\begin{array}{l}-93 \\
-87 \\
-96\end{array}$ & $\begin{array}{r}-3 \\
-1 \\
5\end{array}$ \\
\hline
\end{tabular}

$\mathrm{L}=$ left; $\mathrm{R}=$ righr; $\quad$ Hemi $=$ hemisphere; $\mathrm{BA}=\mathrm{Brodman}$ area; $k=$ cluster extent; $x / y / z=$ Talairach-coordinates, $Z$-values for maximally activated voxels within significant clusters ( $p<.05$ FWE-corrected); voxel threshold $p<.001$ uncorrected, $k \geq 40$, anatomic localization of voxels has been determined using the Talairach Demon Software with the nearest gray matter option enabled (Lancaster et al., 2000), peak voxels within significant clusters are reported.

In bold: peak voxel within significant cluster

Compared to the null-baseline (Fig. 1) this cluster was activated only at a threshold of $p<.005$ in the 2-step condition while no activity was found for the 1-step condition which explains the significant results in the direct comparison.

activity: $Z=4.19 ; 27 /-83 / 21$; inferior and middle occipital gyrus: BAs $17 / 18 ; k=40$; peak activity: $Z=3.95 ; 36 /-93 /-3$ ) and right lateralized in parietal areas (peak precuneus; $B A 7 ; k=61 ; 24 /-62 / 39$; see Table 2 for details).

No increased activity was found for the inverse contrast (1-step nouns $>2$-step nouns).

\section{Discussion}

In the present study we provide insight in the neural network associated with the processing of morphologically derived wordforms. This was accomplished by comparing activity elicited by German nouns with a highly complex internal structure which only differed in the degree of their morphological complexity. That is, the target noun was derived by one or two processing steps from its stem. Given that variables such as word-class, frequency, number of characters or syllables, and task complexity were held constant, a direct comparison of these nouns should reveal the neural substrate supporting derivational morphology.

There is an ongoing debate whether morphologically complex words are stored and retrieved as whole word units from lexical memory or whether complex forms are parsed and accessed via their constituent morphemes. The present results support the decompositional point of view. An intensively discussed aspect concerns the difference in complexity and transparency between structures. For instance, an affix like '-ity' is easily separable from its base (e.g., vane-vanity), so that 'vanity' can be recognized as a derived word. Nevertheless, the surface form may be misleading. if the affixation is not transparent (Marslen-Wilson et al., 1994; Plank, 1994). Since German derivational morphology is rich, it allowed us to compare words with equal surface complexity but differing internal complexity: For instance, the words 'Gleichung' vs. 'Deutung' are both derived from verbs ('gleichen' and 'deuten', respectively)-this derivation is transparent because of the suffix '-ung'. However, the verb 'gleichen' itself is derived from the adjective 'gleich'. The derivation Gleichung thus involves two steps [gleich (Adj) > gleichen $(\mathrm{V})>$ Cleichung $(\mathrm{N})$ ]. In contrast, there is no adjective 'deut, and 'Deutung' is directly (in one step) derived from the verb 'deuten' [deuten $(\mathrm{V})>$ Deutung $(\mathrm{N})]$. The process of deriving the noun 'Cleichung' is thus more complex than that of the noun 'Deutung', even though their surface structure conceals this fact.

This study examined whether the level of morphological complexity is reflected by differential brain activity patterns. So far, previous studies have compared the brain activity for stems and derivations (sincere-sincerity), or for derivations with different types of affixes (insincere-sincerity). This is the first study to compare derivational complexity by using the same affixes. Our results show that the degree of complexity, although not superficially transparent, affects the decomposition process: Thus, the brain computes the degree of a word's complexity.

It might be argued that fundamental differences between the two word types in terms of visual word recognition (i.e., slower reaction times for morphologically more complex words) may have affected our results. Still, the same stimuli were used in a priming study (unpublished data) for other purposes. To get an idea of differences in processing of the two word types, the lexical decision times in the respective conditions (1- and 2-step words in the control condition, i.e., with no priming) have been re-analyzed. Note that contrary to the fMRI study, there were no repetitions of words and the lexical decision was studied in a traditional experimental setup. If there is any fundamental difference in processing the two types of words, it should be rather more pronounced in the behavioural data. The mean lexical decision time for 1-step words was 609.45 
and $611.03 \mathrm{~ms}$ for the 2 -step words. A paired t-test was far from significance $(t=.26 ; p>.78)$.

In line with our a priori hypothesis our results demonstrate that only nouns with a more complex internal structure (2-step nouns) compared to less complex (1-step) nouns elicited increased activity in several brain regions. In particular, these included the left inferior frontal gyrus and middle and superior temporal gyri. Bilaterally increased activity was found in extrastriate inferior and midoccipital regions, additional right hemisphere activity comprised posterior superior and mid-temporal regions and the precuneus. In contrast, no increased activity was found for less complex (1-step) nouns.

As mentioned above, left inferior frontal activity has consistently been implicated with the processing of regularly inflected words (e.g., Miceli et al., 2002; Shapiro et al.. 2001; Tyler, MarslenWilson, et al., 2005: Tyler et al., 2002; Tyler, Stamatakis, Post. Randall, \& Marslen-Wilson, 2006). For derivational morphology, the involvement of this area is less clear cut. For example, in previous studies evidence for morphological processing has been inferred from results of priming studies and yielded controversial results (e.g., Bozic et al, 2007; Devlin et al., 2004; Lavric et al., 2007; Sahin, Pinker, \& Halgren, 2006). This has been explained by the fact that depending on the paradigm used (e.g., delayed vs. immediate priming) different stages of processing might be engaged or neglected. Moreover, our results seem to be inconsistent with those of Davis et al. (2004) who did not find differences between simple monomorphemic words and complex derived or inflected words during a synonym-judgement. Task inherent aspects and the limited number of subjects in their study $(N=10)$ might have been responsible for the lack of (potentially discrete) morphological effects. Moreover, most of the previous studies assessed morphological effects in English. Among Germanic languages, German represents a 'morphologically rich' (synthetic) system by keeping morphological markers to indicate grammatical functions, whereas English is 'morphologically impoverished' (analytic) with mostly syntactic markers for expressing grammatical functions. Indeed, recently it has been demonstrated that morphological effects in German are particularly robust and independent of semantic and form relatedness (Smolka et al., 2009). In this respect, morphological effects in German may differ from those in English and French and other Indo-European languages, where morphological effects have emerged only under the precondition of semantic relatedness.

Moreover, Marangolo et al. (2006) demonstrated an overlap of inflectional and derivational processing in the left IFG, presumably indicative of the morphological parsing process common to both conditions. Additional regions (in BAs 44/45) appeared to be activated by the derivational task which was claimed to represent the increased demands to select an appropriate derivational suffix among a set of alternatives (Thompson-Schill, D'Esposito, \& Kan, 1999). Similarly, we demonstrated common activity in both experimental conditions in the ventrolateral frontal cortex (BA 47), while activity in the more dorsal portions of the inferior and middle frontal gyri (including BAs 44/45) were associated with the processing of 2-step nouns only. Contrary to Marangolo et al. (2006) who employed a generative production task (e.g., produce a derived noun from a verb or adjective), we demonstrate that the reading processes reflect the degree of internal complexity by eliciting additional patterns of activity. This is in line with the claim that any morphologically complex word (or even non-word, see Marslen-Wilson \& Tyler, 2007; Tyler, Marslen-Wilson, et al., 2005) is subjected to an automatic and obligatory decomposition into its stem and affixes. [Note: Even though the task employed in our study does not require explicitly decomposition, morphological effects have been reported previously during lexical decision tasks. Thus, morphological decomposition does not depend on task situations in which morphological processes are explicitly required (Davis et al., 2004).]

Bilaterally increased activity for 2-step nouns was found in the posterior middle and superior temporal gyri. This activity pattern has frequently been reported during single word reading tasks and was linked to semantic and/or phonological processing (e.g. Fiez \& Petersen, 1998; Price, 2000; Turkeltaub et al., 2002). Moreover, bilateral posterior temporal activation has been implicated with lexico-semantic content analysis, i.e., linking sensory inputs to stem-based representations of morphemic form and meaning (Binder et al., 2000: Marslen-Wilson \& Tyler, 2007; Wise et al, 2001). Alternative explanations for the right hemispheric focus of activity have been based on findings suggesting that the RH activation is caused by a broader range of peripherally related meanings. by increased imageability of the stimulus material (Chiarello, Liu, Shears, \& Kacinik, 2002; Coney \& Evans, 2000), or by acoustically based representations during silent articulation (Fiez \& Petersen, 1998). Since the stimuli in our study were matched on morphological neighbours, concreteness, and imageability, and since both conditions potentially involved silent articulation, these proposals are unlikely explanations for our findings. Moreover, the number of words related in meaning (semantic neighbourhood size) in the two sets of derived words was actually higher for the 1 -setp condition ( $69.8 \pm 9.4$; range: $0-45$ ) when compared to the 2 -step condition ( $b$ $5.0 \pm 5.5$; range: $0-22$ ), even though this difference was explained by 4 items with a large number of meaning-related words in the one-step condition $(>20)$. If this had an influence on the present study, one would expect a more pronounced activity pattern for the 1-step condition, which was not the case.

Rather, increased right hemispheric activity specifically associated with more complex nouns is supported by recent data of non-aphasic patients with right hemispheric temporo-parietal damage who demonstrated selectively impaired processing of derivational morphology (Marangolo et al., 2003).

We also found more pronounced activity in the right precuneus and bilateral extrastriate occipital cortices for the processing of the more complex 2-step nouns. The precuneus is part of the so called "default mode system" of the brain (Raichle et al.., 2001) thought to be involved in a variety of higher cognitive functions (e.g., visuospatial imagery, episodic memory retrieval, self-consciousness). Recently, it has been shown that activity in the precuneus is systematically modulated during the processing of auditory and visual verbal information (Wilson, Molnar-Szakacs, \& lacoboni, 2008), linking precuneus activity to the processing or manipulation of higher level linguistic information (Binder et al., 1999). Moreover, the main cortical projections of the precuneus include the lateral frontal lobes and regions in the posterior temporal sulcus (for review see Cavanna \& Trimble, 2006), i.e., structures that exhibited more pronounced activity for nouns with a more complex internal structure in the present study. Thus, activity in this brain area might subserve linguistic processing and be indicative of extralinguistic monitoring/manipulation demands involved in processing the more complex structure of 2 -step derivations.

The bilateral occipital activity pattern is particularly interesting, since the direct comparison of 1- and 2-step derivations was controlled for possible differences between the stimuli in terms of their visual attributes (by the complex letter-string baselines which were derived from the original stimuli). Additionally, the two sets of stimuli were matched for length and number of recognition units (syllables). Therefore, it appears unlikely that differences between conditions can solely be attributed to differences in basic visual features of the two conditions. Rather, posterior middle/inferior occipital areas and adjacent posterior mid-temporal areas have been found to be specifically co-activated during reading with superior temporal activity (cf. Price, 2000, p. 353), possibly providing a link for functional integration of orthographic pro- 
cessing and phonological-semantic analyses (Mummery, Patterson, Hodges, \& Price, 1998; Price \& Mechelli, 2005). Tentatively, it might be speculated whether the co-occurrence of bilateral posterior occipito-temporal and superior temporal activity in the present study represents the afore mentioned activation of stem-based representations of morphemic form and meaning (Marslen-Wilson \& Tyler, 2007) that are enhanced for words that possess a more complex internal structure.

In sum, the present study provides evidence for a large bilaterally organized neural network subserving the processing of complex derivational morphology. While previous studies were mainly concerned with specific subcomponents of this process and their neurofunctional concomitants (i.e., whether morphological processing can be separated from the processing of form and meaning or whether inflectional and derivational morphology activate the same or different structures), we aimed to provide a more complete picture of neuroanatomical structures involved in the processing of derived words: The comparison of otherwise matched words that differ only in their degree of morphological processing demands during a simple lexical decision task potentially (a) avoids several confounds that might have influenced the results of previous studies and (b) provides further evidence for the claim of an automatic and obligatory decomposition of morphologically complex words and the underlying neuroanatomical structures, and (c) provides evidence that the brain is sensitive to the degree of structural complexity.

Clearly, given the complex nature of this process, which involves the actual decomposition of words and the retrieval of lexicalsemantic information (including access to form, meaning and sound characteristics) during word recognition, this cannot be accomplished by a single brain structure. Rather, we provide evidence for a distributed set of structures that seem to be particularly concerned with the concomitants of the morphological parsing of complex words and subsequent lexico-semantic content analysis. These structures were found to be more strongly activated by the more complex words that therefore appear to be similar to the less complex words only at first glance.

\section{Acknowledgements}

This work was supported by grants of the German Foundation of Science (DFG, SFB 471; FOR 341 awarded to CE and the Leibniz Price awarded to AL; MM; ME 3161/2-1). We thank F. Plank and $\mathrm{E}$. Smolka for helpful comments on the final version of the manuscript, $L$. Volberg for help with the selection of the stimuli and N. Zhivolozhnova for transcription of the stimuli and help with the behavioural experiment. Special thanks to M. Uffin for support and inspiration during manuscript preparation. All authors declare that they have no competing financial interests.

\section{Appendix A. Supplementary data}

Supplementary data associated with this article can be found, in the online version, at doi:10.1016/j.neuropsychologia.2009.03.008.

\section{References}

Bentin, S. Feldman, L B. (1990) The contribution of morphological and semantic relatedness to repetition priming at short and long lags: Evidence from Hebrew. Quarterly joumal of Experimental Pychology, 42, 693-711.

Binder, J. R., Frost, J. A., Hammeke, T. A., Bellgowan, P. S. Rao, S. M. Cox. R. W. (1999). Conceptual processing during the conscious resting state. A functional MRI study. Journal of Cognitive Neuroscience, 11, 80-95.

Binder, ]. R., Frost, J. A., Hammeke, T. A., Bellgowan, P. S., Springer, J. A., Kaufman, J. N., et al. (2000). Human temporal lobe activation by speech and nonspeech sounds. Cerebral Cortex, 10, 512-528.

Binder, J. R.. McKiernan, K. A., Parsons, M. E., Westbury, C. F., Possing, E. T., Kaufman. J. N. et al. (2003). Neural correlates of lexical access during visual word recognition. Joumal of Cognitive Neuroscience. 15, 372-393.
Bozic, M. Marslen-Wilson, W. D., Stamatakis, E. A, Davis, M. H. \& Tyler, L. K. (2007) Differentiating morphology, form, and meaning: Neural correlates of morphological complexity. Joumal of Cognitive Neuroscience, 19, 1464-1475.

Cavanna, A. E., \& Trimble, M. R. (2006). The precuneus: A review of its functional anatomy and behavioural correlates. Brain, 129, 564-583.

Chiarello, C. Liu, S., Shears, C., \& Kacinik, N. (2002). Differential asymmetries for recognizing nouns and verbs: Where are they? Neuropsychology. 16, $35-48$.

Coney, 1, \& Evans, $K . \mathrm{D} .(2000)$. Hemispheric asymmetries in the resolution of lexical ambiguity. Neuropsychologia, 38, 272-282.

Davis, M. H. (2004). Units of representation in visual word recognition. Proceedings of the National Academy of Science USA, 101, 14687-14688.

Davis, M. H., Meunier, F., \& Marslen-Wilson, W. D. (2004). Neural responses to morphological, syntactic, and semantic properties of single words: An fMRI study. Brain and Language, 89, 439-449.

Dejong, N. H., Schreuder, R, \& Baayen, H. R. (2000). The morphological family size effect and morphology. Longuage and Cognitive Processes, 15. 329-365.

Devlin, J. T., Jamison, H. L., Matthews, P. M., \& Connerman, L. M. (2004). Morphology and the internal structure of words. Proceedings of the National Academy of Science USA, 101, 14984-14988.

Dominguez, A., de Vega, M., \& Barber, H. (2004). Event-related brain potentials elicited by morphological, homographic, orthographic, and semantic priming. joumal of Cognitive Neuroscience, 16.598-608.

Drews, E. \& Zwitserlood, P. (1995). Morphological and orthographic similarity in visual word recognition. Joumal of Experimental Psychology: Human Perception and Performance, 21, 1098-1116.

Fiez, J. A., \& Petersen, S. E. (1998). Neuroimaging studies of word reading. Proceedings of the National Academy of Science USA, 95, 914-921.

Connerman, L. M. Seidenberg. M. S., \& Andersen, E. S. (2007), Graded semantic and phonological similarity effects in priming: Evidence for a distributed connec tionist approach to morphology. Joumal of Experimental Psychology. General, 136. 323-345.

Lancaster, J. L. Woldorf, M. C., Parsons, L, M. Liotti, M., Freitas, C. S., Rainey, L., et al. (2000). Automated Talairach atlas labels for functional brain mapping. Humon Brain Mapping, 10, 120-131.

Lavric, A. Clapp, A. Rastle, K. (2007). ERP evidence of morphological analysis from orthography: A masked priming study. Journal of Cognitive Neuroscience, $19,866-877$.

Longtin, C. M. \& Meunier, F. (2005). Morphological decomposition in early visual word processing. Joumal of Memory and Language, 53, 26-41.

Longworth, C. E., Marslen-Wilson, W., Randall, B., \& Tyler, L K. (2005). Getting the meaning of the regular past tense; Evidence from neuropsychology. Joumal of Cognitive Neuroscience, 17, 1087-1097.

Marangolo, P., Incoccia, C., Pizzamiglio, L., Sabatini, U., Castriota-Scanderbeg A., Burani, C. (2003). The right hemisphere involvement in the processing of morphologically derived words. Journal of Cognitive Neuroscience, 15 364-371.

Marangolo, P. Piras, F., Galati, G. \& Burani, C. (2006). Functional anatomy of derivational morphology, Cortex, 42, 1093-1106.

Marslen-Wilson, W. D., Tyler, L. K. (2007). Morphology, language and the bra the decompositional substrate for language F comprehension. Philosophical Transactions of the Rayal Society of London B. Biological Sciences, 362 $823-836$.

Marslen-Wilson, W. D., Tyler, L K., Waksler, R., \& Older, L. (1994). Morphology and meaning in the English mental lexicon. Psychology Review, 101, 3-33.

Mechelli, A., Corno-Tempini, M, L, \& Price, C. J, (2003). Neuroimaging studies of word and pseudoword reading; Consistencies, inconsistencies, and limitations. journal of Cognitive Neuroscience, 15, 260-271.

Miceli, G., Turriziani, P., Caltagirone, $C$., Capasso, R., Tomaiuolo, F. \& Caramazza, A. (2002). The neural correlates of grammatical gender: An fMRI investigation. Journal of Cognitive Neurascience, 14,618-628.

Mummery, C. J., Patterson, K., Hodges, J. R., \& Price, C. J. (1998). Functional neuroanatomy of the semantic system: Divisible by what? Joumal of Cognitive Neuroscience, 10, 766-777.

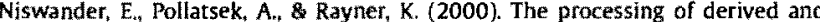
inflected suffixed words during reading. Language and Cognitive Processes, 15 $389-420$.

Oldfield, R. C. (1971). The assessment of handedness: The Edinburg inventory. Neuropsychologia, 9,97-113.

Plank, F. (1994). Inflection and derivation. In R. E. Asher (Ed.), The encyclopedia of language and linguistics (pp. 1671-1678). Oxford; Pergamon Press.

Price, $C$. . (2000). The anatomy of language: Contributions from functional neuroimaging. Joumal of Anatomy, 197, 335-359.

Price, C J. \& Mechelli, A. (2005). Reading and reading disturbance, Current Opinion in Neurobiology, 15, $231-238$.

Pruessmann, K. P. Weiger, M., Scheidegger, M. B., \& Boesiger. P. (1999). SENSE: Sensitivity encoding for fast MRI. Magnetic Resonance Medicine 42, 952-962.

Raichle, M. E. Macleod, A. M., Snyder, A. Z, Powers, W. J., Gusnard, D. A., \& Shulman, G. L. (2001). A default mode of brain function. Proceedings of the National Academy of Sciences USA, 98, 676 -682.

Rastle, K., Davis, M.H. Marslen-Wilson, W. D., \& Tyler, L. K. (2000). Morphological and semantic effects in visual word recognition. Language and Cognitive Processes, 15 , $507-537$.

Rueckl, J., Mikolinski, M., Raveh, M., Miner, C, \& Mars, F.(1997), Morphological priming, fragment completion, and connectionist networks. Journal of Memory and Language, 36, 382-405. 
Sahin, N.T., Pinker, S., \& Halgren, E. (2006). Abstract grammatical processing of nouns and verbs in Broca's area. Cortex, 42, 540-562.

Schreuder, R, \& Baayen, R. H. (1997). How complex simple words can be. journal of Memory and Language, $37,118-139$,

Seidenberg, M. S., \& Gonnerman, L. M. (2000). Explaining derivational morphology as the convergence of codes. Trends in Cognitive Sciences, 4, 353-361.

Shapiro, K. A., Pascual-Leone, A.. Mottaghy, F. M., Gangitano, M. \& Caramazza, A (2001). Grammatical distinctions in the left frontal cortex, foumal of Cognitive Neuroscience, 13,713-720.

Smolka, E, Komlosi, S., \& Rösler, F. (2009). When semantics mean less than morphology: Processing German prefixed verbs. Language and Cognitive Processes. 24, 337-375.

Taft, M., \& Forster, K.L. (1975). Lexical storage and retrieval of prefixed words. Journal of Verbal Learning and Verbal Behavior, $14,638-647$.

Thompsen-Schill, S. L., D'Esposito, M., \& Kan, I. P. (1999). Effects of repetition and competition on activity in left prefrontal cortex during word generation. Neuron, $23,513-522$

Turkeltaub, P, E., Eden, G. F., Jones, K. M. \& Zeffiro, T. A. (2002). Meta-analysis of the functional neuroanatomy of single-word reading: Method and validation. Neuroimage, $16,765-780$
Tyler, L. K., Marslen-Wilson, W. D., \& Stamatakis, E. A. (2005). Differentiating lexical form, meaning, and structure in the neural language system. Proceedings of the National Academy of Sciences USA, 102, 8375-8380.

Tyler, L K, Randall, B., \& Marsien-Wilson, W. D. (2002). Phonology and neuropsychology of the English past tense. Neuropsychologia, 40, 11541166.

Tyler, L. K., Stamatakis, E. A., Post, B., Randall, B., \& Marslen-Wilson, W. (2005). Temporal and frontal systems in speech comprehension: An MRI study of past tense processing. Neuropsychologia, 43, 1963-1974.

Uliman, M. T. (2001). A neurocognitive perspective on language: The declarative/procedural model. Nature Reviews Neuroscience, 2. 717-726.

Wilson, S. M. Molnar-Szakacs, L. \& lacoboni, M. (2008). Beyond superior temporal cortex: Intersubject correlations in narrative speech comprehension. Cerebral Cortex, 18, 230-242.

Wise, R. I, Scott, S. K., Blank, S. C., Mummery, C. J., Murphy, K. \& Warburton, E. A. (2001). Separate neural subsystems within 'Wernicke's area'. Brain, 124, $83-95$. 